\title{
PROCEDURE OF MULTI SLICE COMPUTED TOMOGRAPHY (MSCT) THORAX EXAMINATION USING POSITIVE CONTRAST MEDIA WITH BREAST CANCER CASE
}

\author{
Rosari Janita Limbong1) Siti Masrochah2) Nanang Sulaksono ${ }^{3)}$ \\ 1, RSUD Engku Haji Daud Kepulauan Riau \\ 2,3 Poltekkes Kemenkes Semarang \\ Corresponding author: Rosari Janita Limbong \\ e-mail: rosari.limbong11@gmail.com
}

\begin{abstract}
Background: The protocol for MSCT Thorax examination is axial/coronal/sagittal. The slice thickness parameter has an important role in examining MSCT Thorax in breast cancer cases using contrast media. The thinner the slice thickness, the better the detailed image obtained. The aim of this study is to explain the MSCT Thorax examination procedure in breast cancer cases using positive contrast media, the role of slice thickness in diagnosis and to find out diagnostic information on the MSCT Thorax examination in cancer cases breast.

Methods: This type of research is qualitative with a literature study approach. The data were obtained by identifying the problem then looking for keywords, namely MSCT Thorax, Slice thickness, breast cancer. Literature reviews are carried out through journal search engine searches, such as: Google Scholar, American Journal Rontgenology (AJR), Pubmed, Proquest. The collected journals are reduced based on inclusion criteria so that 3 relevant journals are obtained then analyzed descriptively so that they can answer the objectives to be drawn conclusions.

Results: The results of a literature study show that the MSCT Thorax examination procedure in cases of breast cancer using contrast media is fasting 6 hours before the examination, laboratory checks (urea cratinin within normal limits), releasing all metals in the body, CT scan plane, fixation tools, blankets. , contrast media, injector set.

Conclusion: Contrast media dosage 1-2 ml / kg body weight, flow rate 2-4 ml / s, concentration 300-350 $\mathrm{mgl} / \mathrm{ml}$, patient position supine feet first, upper limit of lung Apex and lower limit of diaphragm (depending on needs), axial cut, coronal, sagittal, the parameters used were $\mathrm{kV}, \mathrm{mAs}$, slice thickness, matrix, WW, WL. A thin slice thickness will provide more accurate diagnostic information and a clear picture of metastases and small lesions can be seen.
\end{abstract}

Keywords: MSCT Thorax, slice thickness, breast cancer.

\section{Introduction}

The highest incidence of cancer in women is breast cancer at 42.1 per 100,000 inhabitants with an average mortality rate of 17 per 100,000 inhabitants followed by cervical cancer of 23.4 per 100,000 inhabitants with an average mortality of 13.9 per 100,000 inhabitants (Ministry of Health, 2019). Breast cancer is the second leading cause of cancer-related death in women worldwide, and the leading cause of cancer-related death in less developed countries. The average prognosis of a person's survival with breast cancer is $85 \%$ in developed countries. Most of the remaining $15 \%$ of patients experience death from metastasis, i.e. the spread of cancer from one part of the body to another (Dictionary of Cancer Term, NCI), because their disease becomes immune to the drug (Veronesi and Goldhirsch, 2017). The percentage demands accurate detection of tumor size and the extent of breast cancer as it is essential for surgical planning and minimizing local recurrence after surgery (Ahn et al., 2013).

Diagnostic imaging is very important to detect the stage of disease in patients with a cancer diagnosis especially to determine the type and 
aggressiveness of treatment options that will be offered to patients (Myers etal., 2006). Computed Tomography (CT) Scan Thorax with contrast media is one of the modalities that plays an important role in breast cancer diagnosis. This examination is not a gold standart so routine screening for patients without symptoms with early stage disease is not indicated. If symptoms arise, appropriate investigations should be requested, for example for bone pain, isotope bone imaging, for shortness of breath, Chest X-Ray (CXR) showing normal radiography results and suspected lympholytis (Barter and Britton, 2014)..

According to (Wijokongko et al. , 2016) Thorax CT Scan with contrast includes scans from $10 \mathrm{~mm}$ pulmonary to supra renal, with a thickness of 5 $\mathrm{mm}$ slices and a reconstruction of $0.6 \mathrm{~mm}$ with intra vein contrast media insertion technique (IV) using injectors of $80-100 \mathrm{cc}$ with a flow rate of 2.5 $3 \mathrm{ml} / \mathrm{s}$. Thorax CT examination is more specifically described in breast cancer cases by Ahn dkk., (2013). The study used $120 \mathrm{ml}$ of Ultravist as a contrast media with monophasic administration at a flow rate of $2-4 \mathrm{ml} / \mathrm{s}$.

IV contrast materials are used for several purposes in CT Scan inspection. These objectives include increasing the atenuation of vessels useful for anatomical localization, distinguishing blood vessels from mass, determining the rate of transfer or invasion of blood vessels by tumors, assessing specific vascular diseases such as aneurysms, stenosis, or loss of blood vessel integrity resulting in theextravasation of contrast media. The increased rate of contrast media is the result of a combination of complex factors, including the level, quantity, and concentration of given contrast materials, injection speed, scanning time, cardiac bulk, plasma expansion, extravascular redistribution, and renal filtration and excretion of contrast materials (Seeram, 2016).. MSCT is very important for its role in cancer imaging screening, kanker,

Thorax's MSCT examination has no preparation for the patient but fills in the informed consent that has been provided. But if the examination uses contrast media then the patient fasts 6 hours before the examination action is carried out andthe laboratory check (ureum cratinin within normal limits), (Bontrager, 2014), MSCT Thorax in breast cancer cases has parameters used including Range between pulmonary apex to diaphragm, Slice thickness $5 \mathrm{~mm}$, FOV $30-50 \mathrm{~cm}$, gantry tilt $0^{\circ}$, exposing factor $180 \mathrm{mAs} 137 \mathrm{kV}$ and algorithm reconstruction at high resolution. With the position of the supine patient on the examination table, the arm is next to the head, thecanning starts from superior as high as clavicula to the sinus costoprenicus posterior. When the patient is suspected with cancer disorders then scanning should include the liver andadrenal glands and use a slice thickness of 5-10 mm (Seeram, 2009).

The inclusion of contrast media should use an injector that is useful for the insertion of contrast media by providing a constant flow rate so that bolus timing is more accurate and enhancement of organs is better. Needles used in injectors measuring 18 or 19 are inserted into medially directed antecubital veins at a flow rate of 5 to $6 \mathrm{ml}$ per second (Seeram, 2009). Whereas based on (Bae, 2006), thecontrast injection protocol on thorax MSCT examination can use two different delay scans, i.e. early (40 seconds) used to see blood vessels in Thorax; or late (55 to 70 seconds) to see thorax soft tissue structure.

According to Jurnal 1 (Yilmaz et al., 2014), that breast cancer patients usually perform Thorax MSCT examinations for the determination of breast cancer stage and for diagnostic indications such as shortness of breath and chest pain. By using a 5 mm slice thickness can already show bronchiektasis in the right pulmonary apex, mass at the mastectomysite, thickening of the left anterior pleural as well as enlargement of the lymph nodes up to the metastasis of the lungs,skeletal and pleural.

According to Journal 2 (Bhalla et al., 2019), that The Toraks CT Protocol is recommended for a variety of clinical indications/ radiologists including its technical parameters as well as the application of new advances in daily clinical scenarios scenario based on the current literature. It can be subdivided into non-contrast CT (NCCT), CT Contrast Enhance (CECT) and then some modifications based on clinical-radiography indications. The use of slice thickness $1.2-1.5 \mathrm{~mm}$ sdh able to show abnormalities in the radiography photos. Contrast media is very useful for determining the firm limits of a disease.

According to Journal 3 (Gossner, 2016), that breast cancer patients to see breast cancer malignancy should perform an MSCT Thorax examination using contrast media using a $1 \mathrm{~mm}$ thicknes slice.

Based on that background, the author is interested in raising the issue into a thesistitled " MSCT THORAX SCREENING PROCEDURE USING MEDIA CONTRAST POSITIVE WITH BREAST CANCER CASES".

\section{Research Methods}


This type of research conducted in this thesis is qualitative research with a study literature approach that aims to find out the role of MSCT Thorax examination in contrast positively with breast cancer cases, to know the role of slice thickness on THORAX MSCT examination and to know the resulting diagnostic information. The research time in this thesis starts from April to May 2020. The type of data used is secondary data. The method of data collection is the study of literature. The method to be used for the study is literature studies. The data obtained is compiled regularly, analyzed, and inferred so as to draw conclusions regarding the study of literature.

\section{Results and Discussions}

Based on the research method of literature studies designed in a similar way, the results are 3 (three) relevant journals, then all three journals will be analyzed. Below are 3 lists of journals to be analyzed, namely

Table1 Relevant literature search

\begin{tabular}{|l|l|l|c|}
\hline $\begin{array}{c}\text { Journal } \\
\text { approval } \\
(2010-2020)\end{array}$ & $\begin{array}{c}\text { Inclusion } \\
\text { Criteria }\end{array}$ & Analyzed & $\begin{array}{c}\text { Relevant } \\
\text { journals }\end{array}$ \\
\hline $\begin{array}{l}\text { Google } \\
\text { Scholar }\end{array}$ & 4 & 1 & \\
\cline { 1 - 3 } Pubmed & 3 & 1 & $\begin{array}{c}3 \\
\text { Journals }\end{array}$ \\
\hline AJR & 3 & 1 & \\
\hline Proquest & 2 & 1 & \\
\hline
\end{tabular}

1. Thorax MSCT screening procedures in breast cancer cases using positive contrast media.

a. Tool Preparation

In the examination of MSCT Thorax in the case of breast cancer using contrast media is necessary the preparation of adequate tools in order for the examination process to run smoothly, while the preparation of tools and protocols and parameters used according to the journal is as follows. Of the four journals analyzed 3 of them discussed diagnostic information, namely Jurnal 1, jurnal 2 and jurnal 3, and 2 of them specifically discussed the procedure of examination of MSCT Thorax in cases of breast cancer.

Table2 Preparation tools used from each literature

\begin{tabular}{|c|l|l|}
\hline No & Literature & \multicolumn{1}{c|}{ Tool Preparation } \\
\hline 1 & $\begin{array}{l}\text { Yilmaz, dkk } \\
(2014)\end{array}$ & $\begin{array}{l}\text { MSCT 16 Slice, injector set, } \\
\text { media kontras }\end{array}$ \\
\hline 2 & $\begin{array}{l}\text { Gossner, } \\
(2016)\end{array}$ & $\begin{array}{l}\text { MSCT 64 Slice, injector set, } \\
\text { media kontras }\end{array}$ \\
\hline
\end{tabular}

\begin{tabular}{|c|l|l|}
\hline 3 & $\begin{array}{l}\text { Bhalla, dkk } \\
(2019)\end{array}$ & $\begin{array}{l}\text { MSCT 16 Slice, injector set, } \\
\text { media kontras }\end{array}$ \\
\hline
\end{tabular}

Table 3 Protocols / Parameters used from each literature

\begin{tabular}{|c|l|l|}
\hline No & Literature & \multicolumn{1}{|c|}{ Protocols / parameters } \\
\hline 1 & $\begin{array}{l}\text { (Yilmaz et } \\
\text { al,2014). }\end{array}$ & $\begin{array}{l}\text { Axial, Sagital } \\
\text { Slice thickness 5 mm, faktor } \\
\text { expose 110-140 kV, mAs 150- } \\
\text { 180, matrix 512x512, FoV 30- } \\
\text { 50, WW 1000-2000 HU, WL } \\
\text { 600-700 HU }\end{array}$ \\
\hline 2 & $\begin{array}{l}\text { Gossner, } \\
(2016)\end{array}$ & $\begin{array}{l}\text { Axial } \\
\text { Slice thickness 1 mm, faktor } \\
\text { expose 137 kV, mAs180, } \\
\text { matrix 512x512, FoV 30-50, }\end{array}$ \\
& $\begin{array}{l}\text { WW 1000-2000 HU, WL 600- } \\
\text { 700 HU }\end{array}$ \\
\hline 3 & $\begin{array}{l}\text { Bhalla, et } \\
\text { al (2019 }\end{array}$ & $\begin{array}{l}\text { Axial, Coronal dan Sagital } \\
\text { Slice thickness 1,2-1,5 mm, } \\
\text { faktor expose 100 kV, mAs } \\
\text { 130-200, matrix 512x512, FoV } \\
\text { 30-50, WW 1000-2000 HU, WL } \\
\text { 600-700 HU }\end{array}$ \\
\hline
\end{tabular}

b. Patient preparation

There was no special preparation on the MSCT Thorax examination of breast cancer cases but patients were asked to change the clothes that had been provided. During the examination, the patient does not use metal tools that may interfere with the radiograph image (Gossner, 2016). According to (Bhalla et al., 2019) examinations that use contrast media should use fasting 6 hours before the examination is carried out and laboratory checks (ureum cratinin within normal limits), this is the same as explaining routine examination techniques according to (Wijokongko et al. , 2016) which requires laboratory examination (the latest results of cratinin ureum within normal limits i.e. ureum $10-50 \mathrm{mg} / \mathrm{dl}$ and cratinin $<1.5$ $\mathrm{mg} / \mathrm{dl})$.

\section{c. Inspection Techniques}

The patient's position according to journal 3 (Bhalla et al., 2019) is that the patient is positioned supine on the examination table with the foot first going into the gantry, both hands are placed on the head, the lungs are symmetrical and placed in the middle of the examination table, both knees are cushioned for the patient's comfort. Then the selection of scano and parameters is needed. In addition, setting parameters, it is certain that the upper limit of the pulmonary Apex and the lower 
limit of the diaphragm enter the examination area and then the scanning process continues.

The patient's position according to journal 2 (Gossner, 2016) is that the patient is positioned as comfortable as possible, with the body position in the middle of the examination table, both hands above the head, the upper limit of the pulmonary apex and the inferior lower limit of the hepar. The patient is instructed to remain silent during the examination and immediately signal if experiencing discomfort, so that the officer will immediately stop the examination.

Obtained 3 journals that each discuss about the examination of MSCT Thorax breast cancer cases using positive contrast media namely journal 1 states that, to detect from breast cancer using a 5 $\mathrm{mm}$ slice thickness is able to enforce the diagnosis of a disease, even metastatic breast cancer can be referred to as the skeletal system which means osteoclas and osteoblasts that cause bone damage, even complications such as spinal cord compression and nerve roots. And to assess the ct value of the chest to determine the size of the breast tumor using pathological measurements as a reference standard.

Before chest CT, contrast media is injected (ultravist $120 \mathrm{ml}$ ) intravenously at a speed of 2-4 $\mathrm{ml} / \mathrm{s}$ into the patient's body. Image analysis is done by thorax radiologists who are trained in subspecialization and radiology residents. Breast CT in this report has precontrast and postcontrast CT scanning techniques at 40 to 65 seconds after contrast administration, which can increaseradiation doses to patients. But judging by the accuracy of tumor size, this study shows that chest CT can be used to look at the size of payudaratumors in patients with breast cancer.

The second journal (Gossner, 2016) states that, MSCT Thorax is recommended for a variety of clinical, radiological indications including breast cancer that can be used in determining a disease. Indications for performing chest $C T$ are clinical or based on abnormalities in previous imaging studies such as chest radiographs (CXR). So all clinical, chest roentgen should be done at first. The findings on CXR will help adjust the CT examination accordingly. Cases of breast cancer often have nodules in the crust and even pleural effuse, with a slice thickness of $1.2-1.5 \mathrm{~mm}$ can be obtained nodules at their peak when toraks inserted contrast media into the body. Various contrast media are available for use in contrast-enhanced CT. For routine contrast $C T$, the contrast media concentration of $300-350 \mathrm{mgl} / \mathrm{ml}$ is sufficient while a higher concentration of $350-400 \mathrm{mgl} / \mathrm{ml}$ is preferred. The contrast media dose to be administered depends on the patient's weight and the current CT dose allows $1-1.5 \mathrm{ml} / \mathrm{kg}$ for use of CT contaminants. Doses up to $2 \mathrm{ml} / \mathrm{kg}$ can sometimes be used with an optimal flow rate of $2-4 \mathrm{ml} / \mathrm{s}$. Contrast media is usually injected intravenously. Usually delayed scanning time 55-70 seconds after the delivery of contrast media to allow optimal soft tissue enhancement. Contrast media is usually injected using a power injector..

The third journal (Bhalla et al., 2019), states that MSCT Thorax is a frequent examination of women in cases of breast cancer. Data shows that one in 250 women undergoing chest CT will have malignant breasts. Radiologists therefore have the opportunity to report a diagnosis orto detect malignant cancer. Using contrast media facilitates the detection of malignant findings because breast cancer shows increased spread, compared to normal tissue. By using a $1 \mathrm{~mm}$ slice thickness and contrast media, the firmness of the radiography image is very clear the difference between normal tissue and the network that has abnormalities. The contrast media used depending on the patient's weight or using contrast media volume is $2 \mathrm{ml} / \mathrm{kg}$ up to a maximum of $100 \mathrm{ml}$. It is divided into the initial bolus two-thirds of the total volume, and the second bolus like three total volumes. To improve the efficiency of contrast media utilization and maintain bolus geometry, flushes are placed between two contrast bolus and follow the second bolus. The intravenous contrast media used is ultravist 320, (Bhalla et al., 2019)..

2. The role of Slice Thickness on Thorax MSCT examination using positive contrast media in breast cancer cases

When Slice thickness is used on MSCT Thorax examination with breast cancer cases it can have an effect on the resulting diagnostik diagnostic information. Where journal 1(Yilmaz et al., 2014), using slice thickness $5 \mathrm{~mm}$, Jurnal 2 , (Gossner, 2016) uses slice thickness $1 \mathrm{~mm}$ and journal 3 (Bhalla, 2019), using slice thickness $1.2-1.5 \mathrm{~mm}$. Sdiedangkan According to (Bontrager,2014), On the examination of MSCT Thorax uses a slice thickness of $5 \mathrm{~mm}$, according to (Seeram, 2009) slice thickness which is used $5-10 \mathrm{~mm}$ on the MSCT Thoraxexamination. Meanwhile, It proves that slice thickness has an important role or advantage to diagnose a disease. According to (Gossner, 2016), that using a $1 \mathrm{~mm}$ slice thickness is very accurate in diagnosing the presence of tumors. Because it is 
able to show the malignancy of breast cancer by using contrast media..

\section{MSCT ImageRy Results}

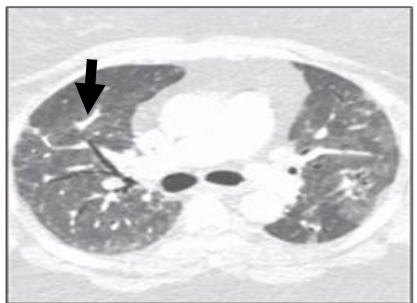

(a)

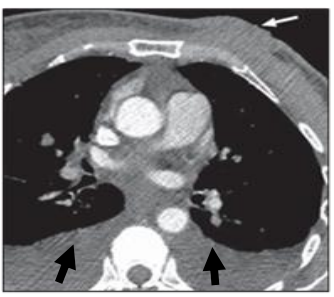

(c))

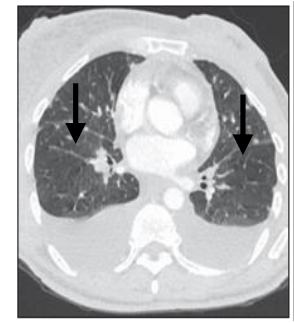

(e)

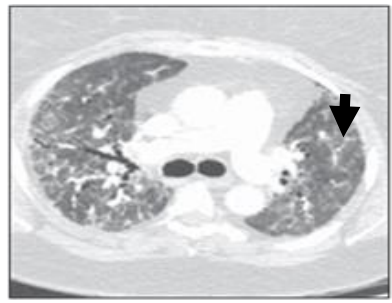

(b)

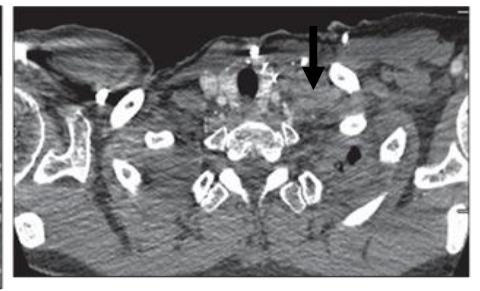

$((\mathrm{d}))$

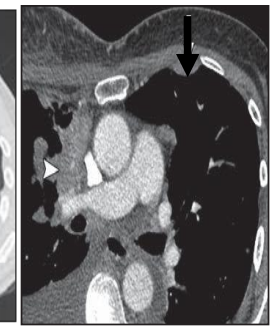

(f)

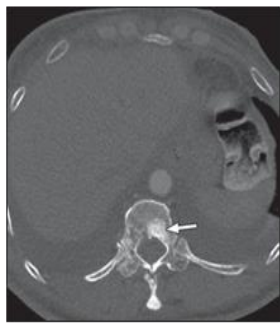

(g)

Figure 1 caption Ct scan scans contrasted with contrast in breast cancer patients, 59-year-old woman (Yilmaz et al., 2014)

Description :

(a) Ct Scan image of axial piece appears to have pulmonary fibrosis

(b) Axial pieces show the absence of pneumonitis

(c) Axial pieces show the absence of bilateral pleural effuse with adjacent atelectasis as well as enlargement of supraclavikula lymph nodes (arrows).

(d) Axial pieces show a mass above the mastectomy (breast removal surgery) (arrow)

(e) Axial pieces show a small number of bilateral non-calcified pulmonary nodules (arrows)

(f) Axial shows thickening of the left anterior pleural (arrow) and enlargement of the mediastinum lymph nodes (arrows)

(g) Axial indicates the absence of sclerotic vertebrae lesions (arrows).

Figure 1 (a) is thorax CT Scan image,looking at both lungfields with the discovery of thickening of the septum and bronchiektasis that develops rapidly

into pulmonary fibrosis. (b) indicates the rapid bilateral and attestational picture of pneumonitis, (c) indicates an abnormality that has led to regional metastasis due to the spread of breast cancer, (d) indicates the influence of the contrast media injected so that the mass can be clearly seen, (e) indicates the metastasis of the lungs that can arise into a single nodule that usually requires a diagnosis of tissue before chemotherapy which is usually more than half the cases of breast cancer of the pulmonary nodules is primary lung cancer, $(\mathrm{f})$ indicates the metastasis of breast cancer in the pleural where often encountered malignant pleural effuse and can reach the nodules of soft tissue or mass, (g) in the CT Scan shows bone metastasis appears as a lithic, sclerotic lesion, which can be covered by the appearance of pathological fractures or compression of spinal medulla. Back pain in breast cancer patients will encourage spidural mass which causes vertebrae compression and epidural metastatic extension..

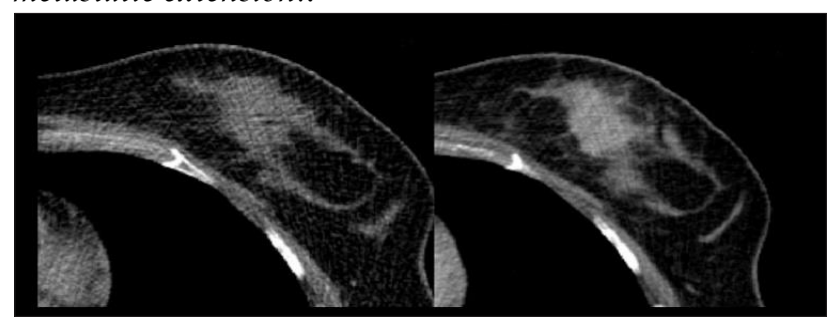

(a)

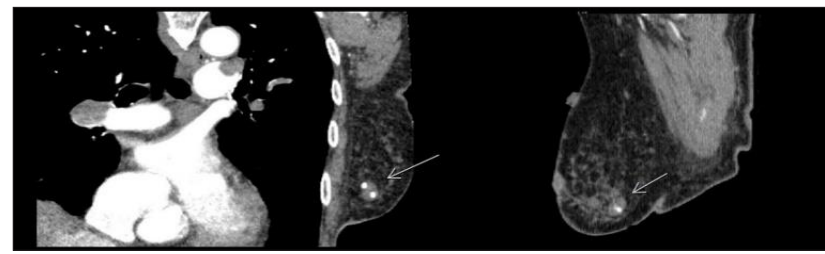

(b)

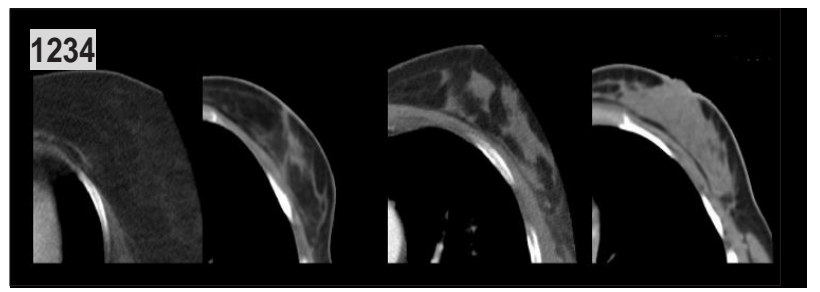

(c)

Figure 2 Results of the CT Scan image of axial pieces, using contrast media on breast cancer, 45Description: year-old woman (Gossner, 2016)

(a) Thorax CT Scan image without contrast media and with contrast media

(b) Axial cut of pulmonary embolism

(c) Axial pieces to look at the type of density of breast cancer 
Figure 2 (a) shows the difference between before and after the injection of contrast media so that the anatomical image is also different from before the injection of mass contrast media found to be less clear while after injecting the contrast media is clearly visible the spread of breast cancer. (b) indicates a clear fibroadenoma in the breast (arrow) that is firmly bordered, a small lesion that increases in density (arrow) which is originally due to pulmonary embolism,(c) indicates different types of breast density in CT Thorax i.e. 1. Density filled with fat, 2 Regions scattered from fibroglandular density, 3 found solid heterogeneous 4. Heterogeneous is getting denser again.

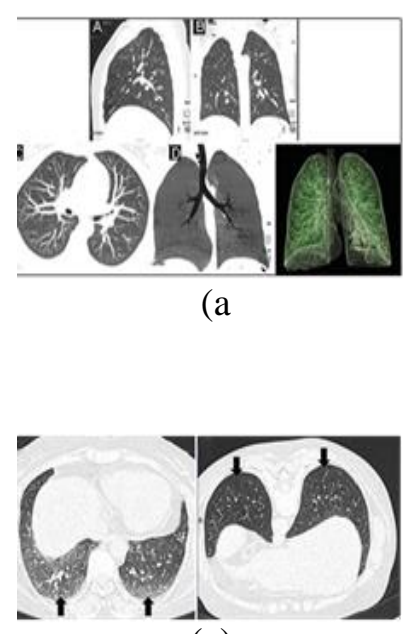

(c)

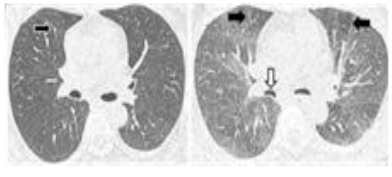

(b)

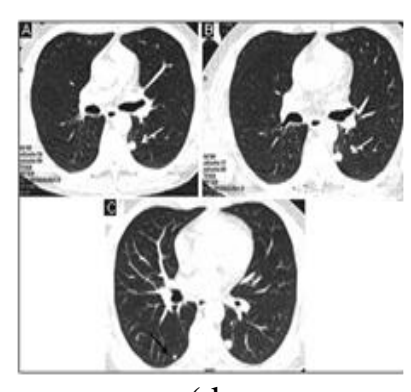

(d
Figure 3 CT Scan of Thorax, a46-year-old woman with a case of breast cancer (Bhalla et al., 2019)

Description:

(a) A-D sagittal and $c$ oronalpieces to show 3 dimensions to assess tracheobronchial airways

(b) A-B without contrast media injection

(c) A. Supne and B prone patients

(d) A. the absence of nodules in the lower left lobe (black arrow)

(e) B. Nodule size change

(f) C. The discovery of small nodules is lobed left down (arrow).

Figure 3 (a) shows the absence of pulmonary nodules and to assess the tracheobronchial airway (display of thegiven volume) for the visualization of the airways, (b) A. pointing out the results before the injection of the media contrasts with the light inspiration (arrow), B shows CTThorax found the air (black arrow) and the posterior wall of the bronchial shows very dense air (white arrow), (c) at the supine position indicates the noise of the posterior basal segment of the bilateral lower lobe (arrow), while the prone position indicates the density of the air (arrow), (d) indicates the absence of nodules in the lower left lobe (white arrow) and after 6 months later in the CT Scan of the chest with the result of a change in size in the nodules while in $\mathrm{C}$ another small nodule (black arrow) is lobed lower right in addition to the nodules of the lower left lobe.

\section{B. Discussion}

1. Thorax MSCT screening procedure in breast cancer cases using positive contrast media

a. Patient preparation

There is no specific preparation on the examination of MSCT Thorax breast cancer cases but because using contrast media the patient is satisfied 6 hours before the examination, the laboratory check (Ureum cratinin within the normal limit that is) and the patient is asked to change the clothes that have been provided and release the metal objects attached to the body.

According to (Bhalla et al, 2019), examination of MSCT Thorax in cases of breast cancer using contrast media should be donefasting 6 hours before the examination is carried out and laboratory checks (ureum cratinin within normal limits) this is in accordance with Wijokongko et al. , 2016 and Bontrager, 2014. The main advantage of fasting is to avoid the side effects of contrasting media injections such as vomiting and dizziness.

\section{b. Tool Preparation}

Preparation tools used in the examination of MSCT Thorax in breast cancer cases using contrast media according to 3 journals are aircraft CT Scan, Injector set and contrast media. According to the authors of the preparation tool in the 3 journals is incomplete that has not mentioned the patient fixation tool andthe patient blanket that serves to reduce the motion an patient as well as thecold in the ct scan because of the room attached air conditioning (AC).

\section{c. Inspection Techniques}

Thorax MSCT screening techniques in breast cancer cases in the journal Yilmaz et al., 2014, Gossner, 2016 and Bhalla et al, 2019 are almost the same as those performed according to Bontrager, 2014 that patients are positioned on their backs (supine) with feet near the gantry (feet first) both hands are above the head, the patient's body is in the middle of the examination table with both lung fields in the middle of the examination table and 
enter the examination area. The longitudinal indicator light is located on the middle line of the body and the indicator lamp is horizontally at the middle of the chest. The patient'shead is cushioned with foam pads and a strap. The patient is instructed to remain silent or motionless during the examination. Then scano and select the appropriate parameters, sesuaithen the scanning process begins. The authors agree with the position of the supine patient, feet first, because the position is the most uncomfortable position of the patient and is not difficult in the inclusion of contrast media.

Based on table 4.3 seen in journal 1 Yilmaz et al., 2014,journal 2 Gossner, 2016 and journal 3 Bhalla et al, 2019 using axial cut protocol while according to John P.Lampignano and E.Kendrick, 2018 for MSCT Thorax examination in irisan breast cancer cases using axial slices. This proves that axial pieces have an important advantage in being able to display the necessary diagnostic information on MSCT Thorax examination of breast cancer cases so that it can be used to enforce diagnoses for further medical action. While the similarities in both John P.Lampignano and E.Kendrick, 2018 and the journal Yilmaz et al., 2014, Gossner, 2016 and Bhalla et al, 2019 use axial pieces. This is because axial pieces are used as a beginning to look pathological. In the object examined is Thorax, axial pieces are one of the main protocols used to confirm the existence of nodules or metastasis because axial pieces or transversal fields are basic pieces on the examination before the sagittal cut is performed.

The authors agree with Thorax's MSCT screening protocol on breast cancer cases in Bhalla et al research,2019 namely axial, coronal and sagittal on the grounds of axial protocol, coronal and agital functionto see thorax pathology of breast cancer cases on some projections so that the metastatic picture can be shown firmly.

2. The role of slice thickness on MSCT Thorax examination of breast cancer cases using positive contrast media..

According to Bontrager, 2014 Slice thickness has an important role to diagnose a disease where the thinner the slice thickness then the better the detail of the image obtained, the higher accuracy and calcification canbe revealed. The thinner the slice thickness will increase spatial resolution but will add signal to noise (seeram, 2016). So that the slice thickness value can be selected between 1-10 mm according to the needs of diagnose. According to
Ballinger 2003, the thinner the slice thickness, the better the detail of the image obtained, so it can be concluded that slice thickness is the ability to distinguish the image between networks during acquisition (slice kolimasi).

According to journals1, 2and 3 bahwa slice thickness are used differently where according to the jurnai 1 slice thickness used $5 \mathrm{~mm}$, journal 2 slice thickness used $1 \mathrm{~mm}$ and journal 3 slice thickness used $1.2-1.5 \mathrm{~mm}$.

The authors argue that slice thickness plays such an important role in diagnosing diseases that there are differences between journals and literature.

3. Diagnostic information on breast cancer cases on Thorax MSCT screening using positive contrast media

Overall based on the results of the three studies above, the use of parameters in thorax MSCT examination in breast cancer cases is important in contrast to the parameters tailored to the needs. The parameters used are very influential with the image information obtained.

According to (Yilmaz et al., 2014) that diagnostik diagnostic information obtained include: Pulmonary embolism, pulmonary nodules, Enlargement of the lymph nodes, pleural effusion, thickening of the septum or nodularity into pulmonary fibrosis, Sclerotic or lytic skelet lesions, Enlarged heart chamber, Pulmonary metastasis, skeletal, pleural.

According to Gossner (2016) that the anatomical image information obtained include: Pulmonary embolism, Small lesions, Large mass with central fat area and edge calcification, Ovoid-increative mass, Pleural Effuse, Incensoma (malignant breast).

According to Bhalla et al, (2019) thatanatomical imagery information obtained include: pulmonary nodules, pulmonary metastasis and to assess the tracheobronchial airways (the display of the given volume) for visualization of the airways. According to Bontrager, 2014 and (Wijokongko et al. , 2016). Pimagery can be seen on Thorax's MSCT examination more accurately using contrast media because the metastatic image is clear and firm.

In this study with studi literature used 3 journals that discussed the examination of MSCT Thorax in cases of breast cancer. Of the 3 journals using aircraft CT Scan 16 slice and 64 slices. With the difference in modality, the possibility of diagnostic information produced is different because the smaller the slice thickness, the optimal diagnostic information is generated. Although this did not affect the results of this study. However, in 
the process of obtaining optimal results, further research needs to be done using the same modalities to produce truly abrasion and relevant diagnostic information.

\section{Conclusion}

1. Msct Thorax screening procedure for breast cancer cases using contrast media in terms of patient preparation, preparation tools and examination techniques is almost the same as msct thorax examination technique in general. Confirmed fasting 6 hours before the examination action is carried out, check the laboratory (ureum cratinin within the normal limit with a ureum value of $10-50 \mathrm{mg} / \mathrm{dl}$ and cratinin $<1,5 \mathrm{mg} / \mathrm{dl}$ )and make surethere are no metal materials in the patient's body. Preparation tools used are CT Scan aircraft, injector sets,contrast media, fixation tools and blankets. Contrast media injection is done intravenously using injector set and total dose of contrast media used 1-2 $\mathrm{ml} / \mathrm{kg}$ body weight, flow rate used is $2-4 \mathrm{ml} / \mathrm{s}$ (adjusting gauge size of IV line and no special division inside, and using contrast media concentration of $300-350 \mathrm{mgl} / \mathrm{ml}$. The patient's position is on the examination table, the foot is near the gantry (feet first), the lung area is in the middle of the examination table, the upper limit of thepulmonary Apex and the lower limit of the Diaphragm (depending on the need). Parameters used $\mathrm{kV}$, mAs, slice thickness,matrix, WW, WL, and axial, coronal and sagittal pieces..

2. The role of slice thickness in THORAX MSCT examination in breast cancer cases using positive contrast media is the thinner the slice thickness then the better the detail of the image obtained, the thinner the slice thickness will increase spatial resolution but will add signal to noise. Which is the value of the slice thickness which is targeted at $1.2-1.5 \mathrm{~mm}$

3. Diagnostic information obtained from the use of contrast media among others is able to evaluate degenerative changes that are very accurate in diagnosing breast cancer malignancy even metastasis that occurs in cases of breast cancer and small nodul can also be seen. It can also show pulmonary embolism, enlargement of lymph nodes, pleural effusion, thickening of the septum or nodularity into pulmonary fibrosis, Sclerotic or lytic skelet lesions, Enlarged heart chamber, Pulmonary metastasis, skeletal.

\section{References}

Ahn, S. J. et al. (2013) 'The value of chest CT for prediction of breast tumor size : comparison with pathology measurement', World Journal of Surgical Oncology. World Journal of Surgical Oncology, 11(1), p. 1. doi: 10.1186/1477-7819-11-130.

Bae, K. T. (2006) 'Principles of contrast medium delivery and scan timing in $\mathrm{MDCT}^{\prime}$, in MDCT: A Practical Approach. doi: 10.1007/88470-0413-6_2.

Bae, K. T. (2010) 'Intravenous contrast medium administration and scan timing at CT: Considerations and approaches', Radiology, 256(1), pp. 32-61. doi: 10.1148/radiol.10090908

Bontrager. (2014). Bontrager's Textbook of Radiographic Positioning and Related.

C.Pearce, E. (2009) Anatomy and Physiology For Anatomi dan Fisiologi Untuk Paramedis. 33 $\mathrm{rd}$ Paramedics .

Ellis, H. and Mahadevan, V. (2013) 'Anatomy and Physiology of the Breast', Surgery (United Kingdom). Elsevier Ltd, 31(1), pp. 11-14. doi: 10.1016/j.mpsur.2012.10.018.

Gossner, J. (2016) 'Intramammary findings on CT of the chest - A review of normal anatomy and possible findings', Polish Journal of Radiology, 81, pp. 415-421. doi: 10.12659/PJR.896312.

Iezzi, R. et al. (2017) 'Tailoring protocols for chest CT applications: When and how?', Diagnostic and Interventional Radiology, 23(6), pp. 420-427. doi: 10.5152/dir.2017.16615.

John P.Lampignano and E.Kendrick, L. (2018) Bontrager Texbook of Radiographic Positioning and Related Anatomy. 9th edn. St.Louis: ANNUR. Available at: www.elsevier.com.

Kang, H. J., Kim, S. W. and Son, S. H. (2017) 'The feasibility of a heart block with an electron compensation as an alternative whole breast radiotherapy technique in patients with underlying cardiac or pulmonary disease', PLoS ONE, 12(9), pp. 1-14. doi: 10.1371/journal.pone.0184137.

Koh, D.-M. et al. (2016) 'Proceedings of the International Cancer Imaging Society (ICIS) 16th Annual Teaching Course', Cancer Imaging. doi: 10.1186/s40644-016-0079-z. 
Nina Siti Mulyani, S. and Nuryani (2013) breast cancer and pms in pregnancy. I. Edited by Haikhi and isna 1. Yogyakarta: Nuha Medika. Available www.nuhamedika.gu.ma.

R.Pabst, R. P. \& (2007) Sobotta, Atlas der Anatomie des Menschen. 22nd edn. Edited by L. Sugiharto. Jakarta: Kedokteran EGC.

Seeram, E. (2009) Computed Tomography Physical Principles, clinical Applications and Quality Control. 3rd edn. Edited by E. Seeram. Canada.

Seeram, E. (2016) Computed Tomography Physical Principles, Clinical Seeram, E. (2019) Digital Radiography: Phisical Prinsiples and Quality Control, Current Problems in Diagnostic Radiology. doi: 10.1016/0363-0188(84)900033.

Seeram, E. (2019). Digital Radiography: Phisical Prinsiples and Quality Control. In Current Problems in Diagnostic Radiology (Vol. 13, Issue 6). https://doi.org/10.1016/03630188(84)90003-3
Snell, R. S. (2012). Clinical Anatomy By System. In EGC.

https://doi.org/10.1017/CBO978110741532 4.004

Sofocleous, C. T. et al. (2007) 'Radiofrequency ablation in the management of liver metastases from breast cancer', American Journal of Roentgenology, 189(4), pp. 883-889. doi: 10.2214/AJR.07.2198.

Suarni, L., Keloko, A. B. and Purba, J. M. (2017) 'The influence of self-efficacy-based health education on students' behavior in early detection of breast cancer', 3 .

Wijokongko, S. et al. (2016) Radiology Protocol Ct Scan and MRI. edn. PARI Central Java Region: Inti Medika Pustaka. Available at: intimedikapustaka@gmail.com.

Yilmaz, Z. N. et al. (2014) 'Imaging of breast cancer-related changes after nonsurgical therapy', American Journal of Roentgenology, 202(3), pp. 675-683. doi: 10.2214/AJR.13.11518. 